\title{
CAPÍTULO 38: AVALIAÇÃO DO LEITE CRU REFRIGERADO DE UMA AGROINDÚSTRIA DE LATICÍNIOS DA SERRA GAÚCHA-RS
}

\section{CHAPTER 38: EVALUATION OF CHILLED RAW MILK FROM A SERRA GAÚCHA DAIRY INDUSTRY}

\author{
Jeferson Aloisio Ströher ${ }^{1}$; Sabrina Caxambu ${ }^{1}$, Joseane Vogel ${ }^{2}$; Luís Carlos Oliveira dos Santos $\mathrm{Jr}^{3}$
}

\section{Resumo}

O leite cru refrigerado precisa ser obtido de maneira higiênica, seguindo protocolos rigorosos para que não haja a possibilidade de alterações em sua composição. Portanto este trabalhoteve como objetivo avaliar parâmetros estabelecidos pela Instrução Normativa (IN) no 76/18 e 77/18 do Ministério da Agricultura, Pecuária e Abastecimento (MAPA), num grupo de 30 produtores de uma Agroindústria da Serra Gaúcha-RS. Foram analisados os parâmetros físico-químicos de gordura, proteína total, lactose anidra, sólidos não gordurosos e sólidos totais, e os parâmetros microbiológicos de Contagem Padrão em Placas (CPP) e Concentração de Células Somáticas (CCS), além de análise de resíduos de produtos de uso veterinário e contaminantes. Os valores encontrados para os parâmetros de CPP em sua maioria estão em acordo com o que preconiza a legislação, porém a CCS parece ser o problema maior dos produtores da região devido aos elevados índices apresentados em 50\% dos produtores avaliados. Também há resultados em desacordo para as análises de proteína, lactose anidra, sólidos não gordurosos. Quanto à detecção de resíduos de antibiótico, nenhum produtor teve resultado positivo, e na detecção de fraudes, 3 produtores apresentaram resultados positivos para o teste de cloretos coincidindo com as maiores taxas de CCS no leite cru refrigerado.

Palavras-Chave: Qualidade do leite, Instrução normativa 76, Instrução normativa 77, Detecção de fraudes, Resíduos de antibióticos

\begin{abstract}
The chilled raw milk must be obtained in a hygienic way, following strict protocols so that there is no possibility of changes in its composition. Therefore, this work aimed to evaluate parameters established by Normative Instruction (IN) 76/18 and 77/18 of the Ministry of Agriculture, Livestock and Supply (MAPA), in a group of 30 producers of an Agroindustry in the Serra Gaúcha - RS. The physical-chemical parameters of fat, total protein, anhydrous lactose, non-fat solids and total solids were analyzed, as well as the microbiological parameters of Standard Plate Count (CPP) and Somatic Cell Concentration (CCS), in addition to the analysis of residues from veterinary products and contaminants. The values found for the CPP parameters are mostly in accordance with the legislation, but the CCS seems to be the biggest problem for the region's producers due to the high rates presented in $50 \%$ of the evaluated producers. There are also results in disagreement for the analysis of protein, anhydrous lactose, non-fat solids. Regarding the detection of antibiotic residues, no producer tested positive, and in the detection of frauds, 3 producers tested positive for chloride, coinciding with the highest rates of CCS in chilled raw milk.
\end{abstract}

Keywords: Milk quality, Normative instruction 76, Normative instruction 77, Fraud detection, Antibiotic residues.

\footnotetext{
${ }^{1}$ Pós-graduação em Ciência e Tecnologia de Alimentos, Universidade Estadual do Rio Grande do Sul, jeferson.stroher@hotmail.com, sabrinacaxambu11@gmail.com

${ }^{2}$ Graduação em Medicina Veterinária, Universidade de Caxias do Sul, jvogel@ucs.br

${ }^{3}$ Doutorado em Engenharia de Alimentos, Universidade Federal de Santa Catarina, luisc.oliveirajr@gmail.com
} 


\section{Introdução}

O leite cru refrigerado é composto por uma combinação de água com diversos elementos sólidos que representam de 12 a 13\% do total do produto. Estes elementos são constituídos por lipídios $(3,5 \%$ a $5,3 \%)$, carboidratos $(4,7 \%$ a 5,2\%), proteínas (3\% a 4\%), sais minerais e vitaminas (1\%), sendo que a forma como estão distribuídos e suas interações são determinantes para a estrutura, propriedades funcionais e aptidão do leite para processamento (BRITO et al., 2009).

A matéria prima quando obtida na ordenha, seja de forma manual ou mecânica, deve seguir protocolos rigorosos de higiene para que evite a possibilidade de alteração na sua composição e em sua qualidade. A falta de higiene na ordenha acarreta aumento de bactérias contaminantes e patogênicas que podem comprometer a qualidade do leite e seus derivados (TRONCO, 2008). Entre os micro-organismos existentes no leite proveniente da ordenha, se destacam os psicrotróficos, mesófilos e termófilos (SAEKI et al., 2010).

Para que haja uma contenção e um controle mais apurado da contaminação no leite cru refrigerado proveniente da ordenha, o advento dos órgãos de fiscalização tem respaldo importante. No Brasil, O Ministério da Agricultura, Pecuária e Abastecimento (MAPA) tem a propriedade para publicar decretos reguladores como a Instrução Normativa (IN) $\mathrm{n}^{\circ} 76$ (BRASIL, 2018), que apresenta o Regulamento Técnico de Identidade e Qualidade (RTIQ) do leite cru refrigerado, alterando itens como a temperatura de recebimento de leite na plataforma que foi reduzida para $7^{\circ} \mathrm{C}$ (anteriormente se admitia até $10^{\circ} \mathrm{C}$ ), e os padrões microbiológicos como a Contagem Padrão em Placas (CPP) (<300.000 UFC/mL) e a Concentração de Células Somáticas $(\mathrm{CCS})(<500.000 \mathrm{CS} / \mathrm{mL})$. Esta legislação também relata que o leite cru refrigerado não deve apresentar substâncias estranhas à sua composição, tais como agentes inibidores do crescimento microbiano. No momento em que for disponibilizado aos consumidores, o leite cru refrigerado não deve conter nenhum contaminante em níveis que coloquem em risco sua saúde (FAO, 2009). O RTIQ da IN 76 também determina os parâmetros físico-químicos que o leite cru refrigerado deve apresentar (BRASIL, 2018). As análises dos parâmetros físico-químicos no leite cru refrigerado são de grande importância pois podem indicar presença de substâncias químicas indevidas que geram alterações na composição do produto final, e assim, podem ser constatadas fraudes ou adulterações, que provocam prejuízos econômicos à indústria e danos à saúde do consumidor. A detecção da ocorrência de leites fraudados é importante para assegurar a qualidade do produto a ser consumido e garantir boas condições de rendimento no processamento de derivados (ROBIM et al., 2012).

Existe ainda o artigo 248 do Regulamento da Inspeção Industrial e Sanitária dos 
Produtos de Origem Animal (RIISPOA) (MAPA, 2017), que considera que o leite deve ter características sensoriais normais, físico-químicas pré-estabelecidas e não deve possuir substâncias estranhas à sua composição. A mesma legislação descreve que os estabelecimentos só podem vender e distribuir produtos que não tenham sido alterados ou fraudados, e complementa que constitui infração alterar ou fraudar qualquer matéria prima, ingrediente ou produto de origem animal, podendo ser considerado impróprio para o consumo humano.

Já a IN no 77 (MAPA, 2018) dispõe que os estabelecimentos devem realizar o controle diário do leite cru refrigerado de cada compartimento do tanque do caminhão, contemplando as análises de pesquisas de neutralizantes de acidez, pesquisas de reconstituintes de densidade ou do índice crioscópico, entre outras análises de composição do leite. Esta mesma instrução normativa relata que o conjunto dos métodos empregados para a realização das análises deve ser capaz de detectar diferentes tipos de neutralizantes de acidez, reconstituintes de densidade, substâncias conservadoras e contaminantes.

Uma preocupação especial na IN n 77 em relação aos resíduos de medicamentos veterinários (RMV) é a crescente disseminação da resistência a antimicrobianos (RAM) em espécies bacterianas que causam doença em humanos, além do desequilíbrio da flora intestinal humana, sendo consequente do uso indiscriminado destes medicamentos em animais de produção e isso tem levado certos países a adotarem medidas de controle rigorosas nesta área, inclusive o Brasil. Esta mesma IN ainda cita que, para a detecção de resíduos de produtos de uso veterinário, a análise deve ser realizada em todos os tanques de cada veículo transportador e que em cada recebimento de leite, deve-se realizar análise de no mínimo dois grupos de antimicrobianos além da análise de leite para todos os grupos de antimicrobianos para osquais existam especificações de triagem analíticas disponíveis.

Portanto, o leite cru refrigerado, estocado nos tanques de refrigeração individuais ou comunitários deve ser coletado para análise em laboratório da Rede Brasileira de Qualidade do Leite (RBQL), com frequência mínima de uma amostra mensal, para avaliação de resíduos de produtos de uso veterinário. Também está descrito na $\mathrm{IN} \mathrm{n}^{\circ} 77$, as análises do leite que a granja leiteira deve realizar antes de cada beneficiamento e a análise para detecção de resíduos de produtos de uso veterinário que deve ser realizada sempre que houver reintrodução no beneficiamento do leite de vacas que finalizaram o período de carência do tratamento com antimicrobianos.

Considerando as atualizações da legislação brasileira (IN n ${ }^{\circ} 76$ e IN n ${ }^{\circ} 77$ ) em relação a produção de leite cru refrigerado e a dificuldade observada pelos produtores na adequação 
aos novos parâmetros legais, o presente estudo tem o objetivo de avaliar o enquadramento de 30 produtores de leite da Serra Gaúcha no Rio Grande do Sul frente aos parâmetros de identidade e qualidade atualizados pelo MAPA.

\section{Materiais e Métodos}

Foram selecionados 30 produtores vinculados a uma agroindústria de 7 municípios da Serra Gaúcha-RS, onde cada produtor forneceu 3 litros de leite (contendo 1L cada) de diferentes pontos do tanque de expansão para a realização das análises de bancada (detecção de resíduos de antibióticos e a detecção de fraudes) mais 4 amostras de leite (contendo $45 \mathrm{~mL}$ ) cada para a realização de análises físico-químicas e microbiológicas em laboratório (RBQL). As amostras foram devidamente codificadas a fim de manter a integridade dos produtores.

A análises de resíduos de antibióticos foram realizadas utilizando os testes da marca Bioeasy®, sendo eles o Kit 4IN1 BTSQ (famílias de antibióticos analisadas: Tetraciclinas, Sulfonamidas, Fluoroquinolonas e Beta-lactâmicos); Kit 2IN1 BTCef (famílias de antibióticos analisadas: Beta-lactâmicos, Cefalexina e Tetraciclinas); 4 em 1- BTSQ (famílias de antibióticos analisadas: Beta-lactâmicos, Tetraciclinas, Sulfonamidas e Quinolonas) e o Kit 3IN1 (Quinolonas, Lincomicina e Tilosona). A legislação brasileira (BRASIL, 2018) explana que na recepção do leite cru refrigerado deve-se realizar no de no mínimo dois grupos de antimicrobianos. Para a detecção de fraudes no leite cru refrigerado foram realizados os testes de: presença de cloretos, substâncias redutoras voláteis (álcool etílico), amido, determinação de peróxido de hidrogênio e formaldeído conforme o Manual de Métodos Oficiais para Análise de Alimentos de Origem Animal (BRASIL, 2018). As análises de neutralizantes de acidez metodologia A e B, cloro e hipocloritos e para a detecção de sacarose foram realizados conforme preconizado pelo MAPA (BRASIL, 2006).

As análises físico-químicas e microbiológicas foram realizadas em laboratório externo credenciado pelo MAPA (Unianálises, Lajeado-RS) E foram realizadas as seguintes análises: CPP, CCS, gordura, lactose anidra, sólidos não gordurosos e sólidos totais de acordo com metodologia oficial conforme a IN 77 (BRASIL, 2018).

Todas as análises de bancada foram realizadas em triplicata (detecção de fraudes e resíduos de antibióticos) e as análises em RBQL (CPP, CCS, gordura, lactose anidra, sólidos não gordurosos e sólidos totais) em duplicata foram e calculadas a sua média \pm desvio padrão.

\section{Resultados e Discussão}

A qualidade do leite cru refrigerado pode ser avaliada em relação a sua composição 
nutricional, sanitária e higiênica no processo de ordenha sendo que todos os produtores avaliados no estudo possuem ordenha mecanizada e tanques de resfriamento do tipo expansão, contribuindo para um leite de melhor qualidade. A determinação das contagens de microorganismos no leite é de grande importância para avaliar a higiene da ordenha, a saúde dos animais e as condições de estocagem e transporte do leite cru. Além disto, o leite com elevada contagem bacteriana representa risco para a saúde do consumidor, pelo potencial de veicular micro-organismos patogênicos e toxinas microbianas (GERMANO E GERMANO, 2001). Em relação a infecções intramamárias, a contagem de células somáticas (CCS) é utilizada em âmbito mundial para identificar vacas com mastite (COSTA et al., 2017).

Os pontos mostrados para as análises de CPP e CCS (Figura 1) mostram que a grande parte das amostras de CCS estavam acima do limite máximo do que preconiza a legislação brasileira (BRASIL, 2018), enquanto, os dados de CPP poucos estiveram acima da legislação (BRASIL, 2018). Dos 30 produtores analisados, 15 (50\%) apresentaram contagens de CCS acima do permitido pela legislação (BRASIL, 2018). As contagens mais elevadas de CCS foram $1.236 \times 10^{3} \pm 3$ e $1.217 \times 10^{3} \pm 2 \mathrm{CS} / \mathrm{mL}$, respectivamente e as menores $27 \times 10^{3} \pm 1$ e $28 \times 10^{3} \pm$ $1 \mathrm{CS} / \mathrm{mL}$, respectivamente.

Figura 1. Contagem de micro-organismos pelos métodos CPP e CCS em leite cru refrigerado considerando os

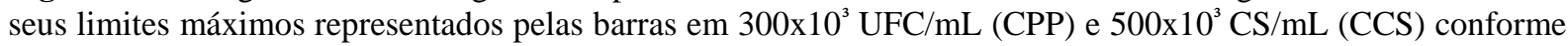
a IN 76 (BRASIL, 2018).

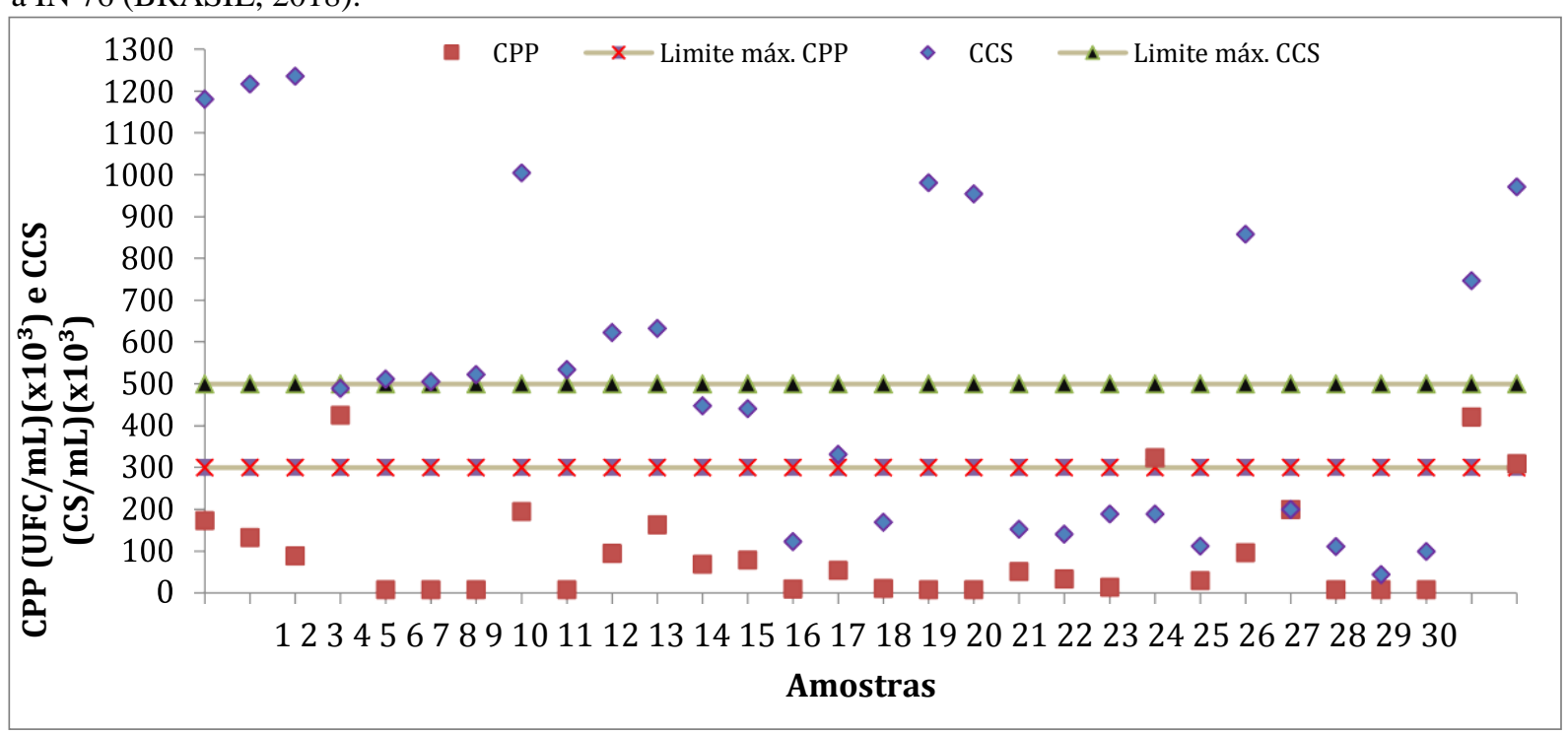

Fonte: Própria (2020).

A CCS é o mecanismo pelo qual se avalia a incidência e prevalência de mastite nos rebanhos leiteiros. O controle da mastite bovina é uma ação multifatorial, que se faz necessário para gerar resultados eficientes, além do incentivo financeiro, de mecanismos que modifiquem 
a atitude e o comportamento das pessoas relacionadas ao manejo preventivo. Esses mecanismos podem ser trabalhados através de programas de treinamentos, oficinas, campanhas de comunicação em massa e reforçar a pressão social, melhorando a percepção do produtor frente a importância da mastite (CASSOLI, 2012; ESGUERRA, 2014).

As amostras com elevadas CCS podem ter sido afetadas pela mastite, visto que é um dos principais desafios encontrados nos rebanhos leiteiros no mundo, por acarretar perdas econômicas aos produtores relacionadas aos tratamentos, redução da produção e qualidade do leite, além do possível descarte de animais. No Canadá, somente no ano de 2013, $20 \%$ das vacas foram abatidas involuntariamente, devido a problemas com mastite clínica ou por alta CCS (MARTIN et al., 2018). No Brasil, cerca de 49\% dos rebanhos monitorados em 2012 apresentaram CCS acima de $400.000 \mathrm{CS} / \mathrm{mL}$ em tanques de resfriamento de leite, indicando uma alta prevalência de mastite segundo o reportado por Cassoli (2012).

Coentrão et al. (2008), ao avaliarem a CCS de amostras individuais de leite cru de 2.657 vacas, em 24 rebanhos no estado de Minas Gerais, descrevem valores médios de CCS de $608 \times 10^{3} \pm 967 \times 10^{3} \mathrm{CS} / \mathrm{mL}$. Martins et al. (2015) analisaram 5.758 amostras de leite de vacas individuais de 7 propriedades do Estado de Goiás e a CCS média dos rebanhos com mastite subclínica foi de aproximadamente $743 \times 10^{3} \mathrm{CS} / \mathrm{mL}$. Vallin et al. (2009) encontraram média de CCS de $6,08 \times 10^{5} \mathrm{CS} / \mathrm{mL}$ em leite cru obtido a partir de ordenha manual em 19 municípios da região central do Paraná. Lima et al. (2006), por sua vez, encontraram média de 4,02 x $10^{5}$ $\mathrm{CS} / \mathrm{mL}$ na região Agreste de Pernambuco. Todos estes autores obtiveram médias de CCS semelhantes aos mais altos índices apresentados neste trabalho, podendo indicar que a mastite subclínica está presente em boa parte dos rebanhos dos produtores da Serra Gaúcha.

Dos 30 produtores analisados, $4(13,3 \%)$ apresentaram Contagem padrão em placas (CPP), acima da legislação brasileira (BRASIL, 2018), que é $\leq 300.000 \mathrm{UFC} / \mathrm{mL}$. Os maiores resultados foram $421 \times 10^{3} \mathrm{e} 427 \times 10^{3} \mathrm{UFC} / \mathrm{mL}$ respectivamente, enquanto os menores resultados foram > $8 \mathrm{UFC} / \mathrm{mL}$. A CPP elevada indica uma alta contaminação de micro-organismos presentes no leite como reportado por Fagan et al. (2008) que relata ainda que a CPP elevadaé indicativa da carência de higiene de ordenha, dos equipamentos e utensílios. Oliveira et al. (2010) encontraram para CPP a média de 3,7 x 103 UFC/mL nas 11.523 amostras de leite cru estudadas por eles no município de Vassouras, Rio de Janeiro, bem abaixo do que estipula a legislação e condizente com a maioria dos produtores avaliados neste trabalho. Porém, Vallin et al. (2009) encontraram média de CPP de 1,6 x 106 UFC/mL em leite cru obtido em ordenha manual e 4,2 × $10^{6} \mathrm{UFC} / \mathrm{mL}$ em leite obtido em ordenha mecânica. Lima et al. (2006) 
encontraram média de CPP de 3,2 x $10^{8} \mathrm{UFC} / \mathrm{mL}$ em sistemas de ordenha manual no agreste de Pernambuco. Eckstein et al. (2010) comparou as contagens de CPP nos diferentes tipos de refrigeração, constatando que as menores contagens foram encontradas em tanques de expansão $\left(2,33 \times 10^{5} \mathrm{UFC} / \mathrm{mL}\right)$, seguidos por tanques de imersão $\left(1,19 \times 10^{6} \mathrm{UFC} / \mathrm{mL}\right)$ e freezers $(1,26 \mathrm{x}$ $10^{6} \mathrm{UFC} / \mathrm{mL}$ ). Segundo a IN 76 (MAPA, 2018), as indústrias de laticínios somente podem adquirir leite cru refrigerado de produtores que possuírem tanques de expansão, não sendo mais permitidos os tanques de imersão e freezer pois são de difícil higienização. Estas avarias nos resultados podem ser explicadas por uma inexistência ou ineficácia das Boas Práticas Agropecuárias entre os produtores (BRASIL, 2017).

A análise dos demais parâmetros preconizados da legislação estão representados nas Figuras 2 e 3, onde pode-se observar a conformidade quanto ao teor de gordura em todas as amostras, uma vez que a legislação brasileira determina que o teor deva ser $\geq 3,0 \mathrm{~g} / 100 \mathrm{~g}$ (MAPA, 2018). O teor de gordura estando em conformidade com a legislação é positivo para a agroindústria pois a empresa pode produzir natas, cremes de leite e derivados lácteos com maior rendimento e qualidade. Já para a análises de proteína, duas amostras apresentaram 2,88 $\pm 0,1$ g/100 g de conteúdo proteico, estando em desacordo com o padrão mínimo da legislação brasileira que é $\geq 2,9 \mathrm{~g} / 100 \mathrm{~g}$ (BRASIL, 2018) e com resultados semelhantes à Teixeira et al. (2003) que verificaram teores de proteína abaixo da legislação em 3,14\% em amostras de leite de vacas da raça Holandesa. O teor de proteína no leite pode variar devido à raça do animal e a época do ano (DÜRR, 2004).

Lima et al. (2006) encontraram média de 3,54\% de gordura nas 31 amostras estudadas do Agreste de Pernambuco, semelhante à Pereira et al. (1999) que encontraram média de gordura de 3,64\% nas 6.112 amostras de leite cru analisadas, que também relataram média de 3,32\% de proteína. Zanela et al. (2006) avaliando a qualidade do leite em sistemas de produção na região Sul do país verificaram média de proteína de 3,42 g/100g, semelhante a maior parte dos produtores selecionados por este trabalho. Com relação ao percentual de lactose, Lima et al. (2006) encontrou média de 4,47\% nas 31 amostras de leite cru refrigerado estudadas no Agreste de Pernambuco.

Quanto ao teor de lactose anidra, 3 amostras estiveram abaixo do limite mínimo $(\geq 4,3$ $\mathrm{g} / 100 \mathrm{~g}$ ) estipulado pela legislação brasileira (BRASIL, 2018), tendo seu resultado em (4,08, 4,27 e 4,28 g/100 g, respectivamente). As concentrações de lactose no leite dependem, principalmente, da glicose que é produzida no fígado a partir do ácido propiônico produzido no rúmen, ácido este produzido em maior proporção quando quantidades adequadas de 
concentrado são fornecidas aos animais (PEREIRA, 2000). O padrão de lactose abaixo da legislação brasileira (BRASIL, 2018), pode estar relacionada à regulação da pressão osmótica na glândula mamária, de forma que a maior produção de lactose determina maior produção de leite (PERES, 2001). Campos et al. (2006) verificaram que, assim como o teor de gordura do leite diminui quando a produção do leite aumenta, o mesmo comportamento acontece com a lactose embora a lactose é o componente menos afetado com a oscilação do volume de leite. A diminuição da lactose em três amostras analisadas no presente trabalho em níveis abaixo do padrão da legislação (BRASIL, 2018), sugerem adição de água, uma vez que este é o componente mais estável do leite (SANTOS; FONSECA, 2007).

Eifert et al. (2006) relataram que a lactose é o principal e o mais importante componente osmótico do leite, por estar diretamente ligado a secreção de água e ao volume de leite produzido, além de ser um componente dependente de glicose para a sua síntese. No entanto, quando há menor proporção de lactose no leite, sugere-se que provavelmente o animal esteja com deficiência de glicose, logo se observa a tendência a menor produção de leite.

Bueno et al. (2005) observaram uma redução do teor de lactose à medida que a CCS aumentou, o mesmo foi constatado neste estudo, sendo que os produtores que tiveram o teor de lactose abaixo da legislação, também apresentaram a análise de CCS acima do padrão legal (BRASIL, 2018). Auldist (1995) também verificou redução na concentração de lactose, relacionada ao aumento da CCS. O autor atribui a redução da porcentagem de lactose a menor síntese deste componente do leite em glândulas mamárias infectadas e da perda de lactose da glândula para a corrente sanguínea, associado ao aumento da permeabilidade da membrana que separa o leite do sangue, o que provoca a excreção da mesma na urina (PEREIRA, 2000).

Quatro amostras de leite não atenderam os padrões da legislação para ESD (g/100 g), mas todas as amostras atenderam a legislação para EST (g/100 g) no leite cru refrigerado, considerando os seus limites máximos (BRASIL, 2018) em $(\geq 8,40$ e $\geq 11,40$ g/100 g, respectivamente). A variação de sólidos totais está diretamente ligada à variação da gordura (PERES, 2001). Reis et al. (2007), analisando amostras de leite cru obtidas a partir de ordenha manual e mecânica, verificou os teores médios de ESD de 8,59 g/100g e 8,25 g/100g, respectivamente, mostrando que a ordenha manual é melhor para este parâmetro. Valores superiores aos observados neste trabalho foram observados por Silva (2003), com resultados médios de $8,71 \%$ (manual) e 8,48\% (mecânica), evidenciando uma maior concentração desse componente quando a ordenha era realizada manualmente, o que está de acordo com os resultados apresentados neste trabalho. 
Figura 2. Teor de gordura (g/100g), proteína $(\mathrm{g} / 100 \mathrm{~g})$ e lactose anidra $(\mathrm{g} / 100 \mathrm{~g})$ nas amostras considerando os seus limites mínimos representados pelas barras em $(3,0 \mathrm{~g} / 100 \mathrm{~g}, 2,9 \mathrm{~g} / 100 \mathrm{~g}$ e 4,3 g/100g, respectivamente) de acordo com o RTIQ para leite cru refrigerado (BRASIL, 2018).

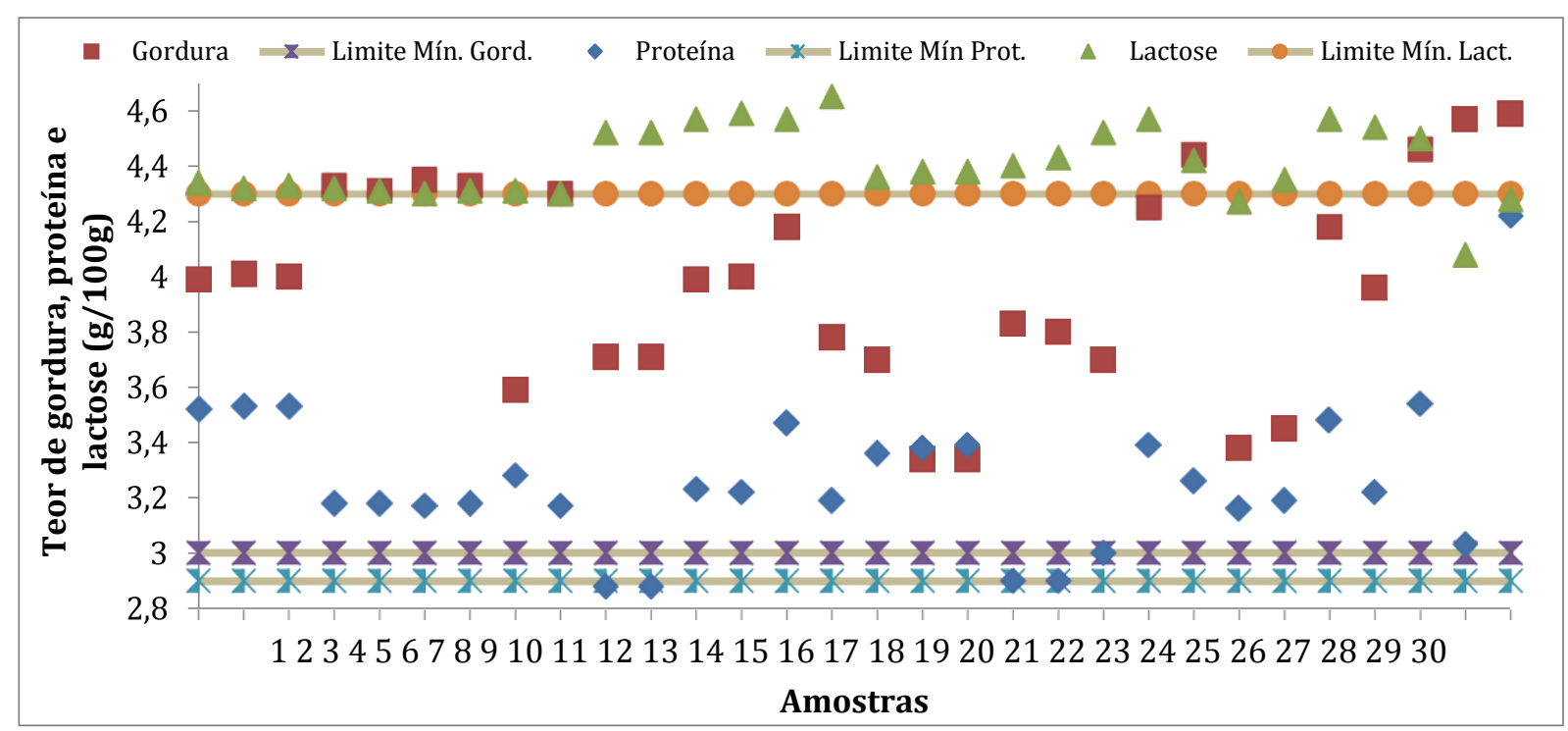

Fonte: Própria (2020).

Figura 3. Teor de sólidos totais (EST) (g/100g) e sólidos não gordurosos (ESD) (g/100g) nas amostras considerando os seus limites mínimos representados pelas barras em $(8,40 \mathrm{~g} / 100 \mathrm{~g}$ e $11,40 \mathrm{~g} / 100 \mathrm{~g}$, respectivamente) de acordo com o RTIQ para leite cru refrigerado (BRASIL, 2018).

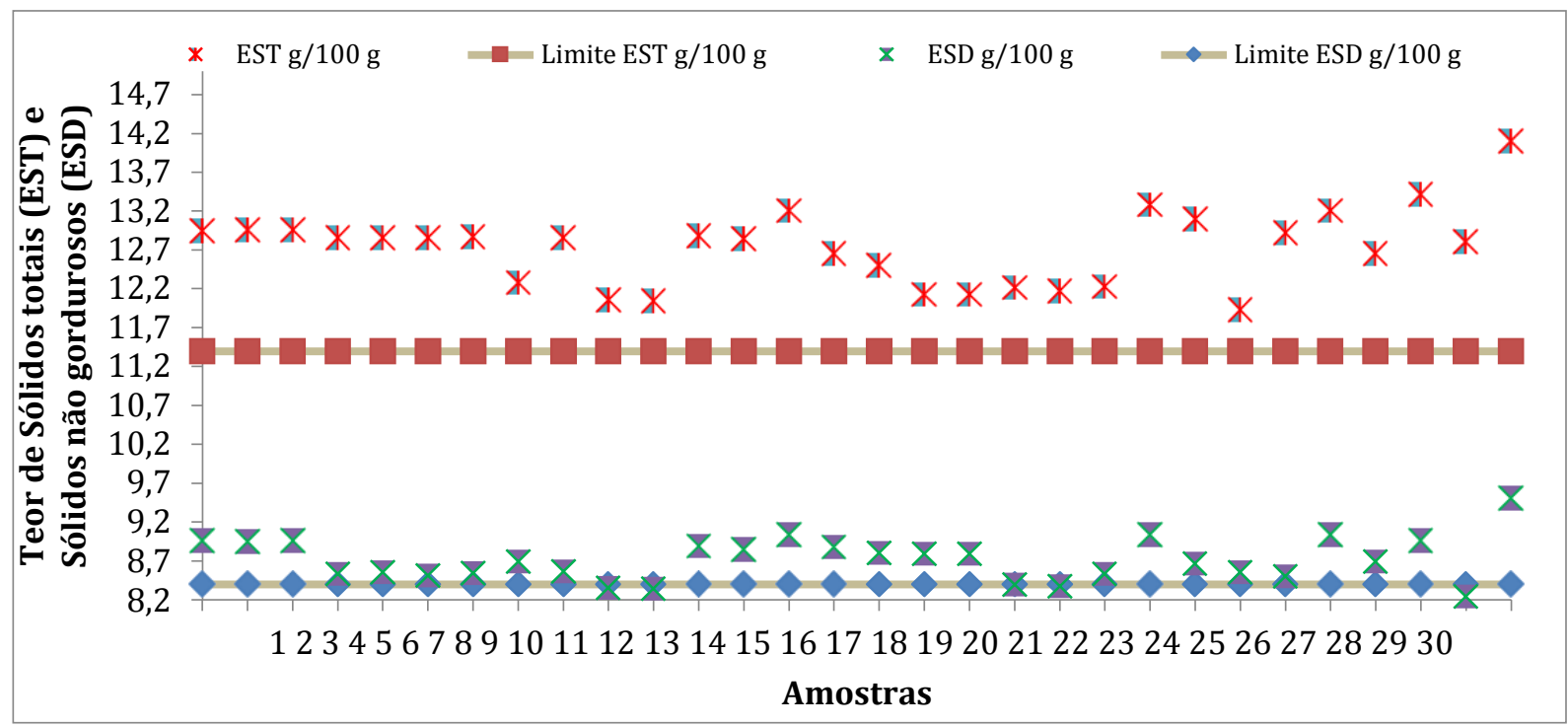

Fonte: Própria (2020).

Quanto às análises de fraudes, a presença de cloretos foi detectada em três amostras. Este teste também é utilizado para detectar adição de água ao leite. O resultado deste trabalho pode ter relação com as taxas mais elevadas de CCS do experimento que consequentemente, resultam em alto teor de cloretos levando a um resultado falso-positivo para fraudes. A alta taxa de CCS é uma das formas utilizadas para detectar a mastite subclínica, uma vez que, o leite de [595] 
um animal que apresenta esta patologia pode sofrer uma série de alterações na sua composição físico-química, incluindo o aumento dos teores de cloro e sódio que estão presentes na circulação sanguínea do animal, e chegam ao leite através dos capilares sanguíneos. (FORNASARI; MONTANHINI, 2015).

Não foram encontradas a presença de formaldeído, neutralizantes de acidez, sacarose, álcool etílico, peróxido de hidrogênio e cloro e hipocloritos nas 30 amostras analisadas do experimento.

Fimino et al. (2010) analisaram 60 amostras de leite cru refrigerado e detectaram a presença de formol em 13\% das amostras. Fimino et al. (2010) em estudo com leite cru dos tanques de expansão, verificaram presença de formol e de nitrato em 13,0 \% e 40,0 \% das amostras, respectivamente.

A análise de neutralizantes de acidez é realizada devido a adição de substâncias alcalinas no leite, já que estas substâncias têm por finalidade neutralizar a acidez do leite e mascarar uma possível qualidade microbiológica insatisfatória (AMORIM, 2017). A adição fraudulenta de neutralizantes como o bicarbonato de sódio ou o hidróxido de sódio visa ocultar a elevação da acidez do leite a níveis acima dos permitidos pela legislação (TRONCO, 2008).

A análise de sacarose verifica a presença de açúcar no leite. É uma fraude muito comum, pois a presença das substâncias sólidas adicionadas aumenta a densidade do leite aguado (FERRÃO et al., 2007).

A adição de cloro e hipoclorito ao leite pode ser considerada uma fraude comum, já que devido ao seu baixo custo e amplo espectro de ação são frequentemente empregados na higienização de equipamentos de ordenha e laticínios (CORDS et al., 2001; TRONCO, 2008). Robim (2011) e Tamanini (2012) também encontraram resultados negativos para o teste de cloro e hipocloritos. Sua adição intencional ao leite pode representar risco à saúde do consumidor (EPA, 2000).

Firmino et al. (2010) verificando o uso de reconstituintes da densidade, não observaram presença de amido, entretanto, foram observados resultados positivos para análise de sacarose em $6,0 \%$ das amostras, e em 36,0 \% das amostras para análise de cloretos.

Nenhuma amostra de leite cru refrigerado avaliada apresentou resultado de antibióticos positivo constando assim, um rigoroso controle destes produtos na localidade estudada. $\mathrm{Na}$ indústria de laticínios a presença de resíduos de antimicrobianos no leite pode gerar efeitos microbiológicos indesejáveis, como a inibição da microbiota (interferência das características sensoriais e tecnológicas dos produtos lácteos industrializados), causando perdas econômicas 
(BRITO et al., 2000). A pesquisa de Neta et al. (2016) que constataram ausência de resíduos da classe beta-lactâmicos e tetraciclina em todas as amostras, está em acordo com o presente trabalho, visto que não houve detecção de resíduos de antibióticos nas amostras.

Alguns autores encontraram pequenas, mas significativas quantias de antibióticos no leite cru refrigerado, como Almeida et al. (2003) que verificou 1,89\% amostras positivas de antibióticos, semelhante ao encontrado por Ribeiro et al. (2009), que observou 2,7\% de amostras positivas. Já Silva et al. (2012) verificou quantias de antibióticos em apenas em 1,10\% nas amostras analisadas.

Diversos trabalhos da literatura relataram altos resíduos de antibióticos em leite cru refrigerado, como Nero et al. (2007) que avaliaram 210 amostras de propriedades rurais de quatro estados (MG, RS, PR e SP), utilizando o Charm-test e constataram 11,5\% das amostras positivas. Em experimento de Nascimento et al. (2011), 50\% das amostras tiveram resultados positivos, sendo 34,8\% para a família de antibióticos Beta-lactâmicos.

Elevados índices de resíduos de antibióticos também foram relatados por Rosa e Queiroz (2007) que observaram 15\% de amostras positivas para resíduos de antibióticos da família dos beta- lactâmicos. Macedo et al. (2009) analisando 103 propriedades leiteiras, detectaram um total de 11 amostras positivas (10,68\%) no leite cru refrigerado. Raia Jr. (2001), analisando 60 amostras de leite cru refrigerado em tanques de resfriamento detectou 9 (15\%) amostras positivas. Aguiar et al. (2016) ao analisarem amostras de leite provenientes de 15 tanques de refrigeração utilizando o teste eclipse $50 ®$, constataram que $26,7 \%$ das amostras foram positivas na detecção de resíduos de antibióticos. Albuquerque et al. (1996) observaram 69,7\% das amostras contendo substâncias antimicrobianas em leite cru refrigerado.

\section{Conclusões}

Dos 30 produtores analisados, $10(33,3 \%)$ estiveram em conformidade com todas as análises realizadas neste experimento e atenderam à legislação brasileira (BRASIL, 2018). Quanto a análise de CCS, 15 (50\%) produtores não atenderam o que preconiza a legislação (BRASIL, 2018), provavelmente pela alta incidência de mastite no rebanho leiteiro. Para a análise de CPP somente 4 (13,3\%) produtores não atenderam a legislação brasileira (BRASIL, 2018). Quanto as demais análises: proteína 2 (6,6\%), sólidos não gordurosos 5 (16,6\%), e lactose anidra $3(10 \%)$ não atenderam o que preconiza o RTIQ do leite cru refrigerado (BRASIL, 2018).

Nas amostras onde houveram, resultados positivos para o teste de cloretos, também 
tiveram os maiores resultados para a análise de CCS. E não houve a presença de resíduos de antibióticos nas amostras estudadas.

Os produtores e as indústrias receptoras precisam buscar conhecimento, aprimorar o manejo sanitário do rebanho e de ordenha, para melhorar a produtividade, a saúde animal e evitar descarte de leite, visando produzir com mais segurança e qualidade para o consumo e processo. Nas propriedades avaliadas neste trabalho, poucas adequações se mostram necessárias para estar em conformidade com os itens atualizados da legislação brasileira para leite cru refrigerado.

\section{Referências}

AGUIAR, G. S. et al. Avaliação da presença de antibiótico em leite cru refrigerado. Revista UNIVAP, São José dos Campos-SPBrasil, ISSN 2237-1753. v. 22, n. 40, Edição Especial 2016. Disponível em: https://revista.univap.br/index.php/revistaunivap/article/view/952. Acesso em: 25 jul. 2020.

\section{ALBUQUERQUE, L.M.B.; MELO, V.M.M.; MARTINS, S.C.S. Investigações sobre a} presença de resíduos de antibióticos em leite comercializado em Fortaleza-CE-Brasil. Higiene Alimentar, São Paulo, v.10, n.41, p.29-32, 1996.

ALMEIDA, L.P. et al. Resíduos de Antibiótico em Leite de Propriedades Rurais da Região de Uberlândia-MG. Biosci. J., Uberlândia, v.19, n. 3, pág. 83-87. 03 maio 2006. Disponível em: http://www.seer.ufu.br/index.php/biosciencejournal/article/view/6472. Acesso em: 25 jul. 2020 .

ALVAREZ, Juan Camilo Esguerra. O homem como fator de risco da mastite. 2014. 63 f. Dissertação (Mestrado) - Curso de Engenharia Agrônoma, Universidade de São Paulo, [S.1.], 2014. Disponível em: https://teses.usp.br/. Acesso em: 25 jul. 2020.

AMORIM, A.L.B.C. Avaliação da presença de substâncias químicas em leites cru e beneficiado produzidos e comercializados no Distrito Federal e Entorno. Brasília: Faculdade de Agronomia e Veterinária, Universidade de Brasília, 2017, 49p. Dissertação de Mestrado. Disponível em: https://repositorio.unb.br/handle/10482/23637. Acesso em: 25 jul. 2020. 
AULDIST, M. J. Changes in the compositional of Milk from healthy and mastitic dairy cows during the lactation cycle. Australian Journal of Experimental Agriculture, Melbourne, v. 35, n. 4, p. 427-436, 1995.

BIOEASY®. Bioeasy Milk Antibiotic Rapid test kits. Disponível em:

http://en.bioeasy.com/?page id=1148. Acesso em: 25 jul. 2020.

BRASIL. Ministério da Agricultura Pecuária e Abastecimento. (2018) Instrução Normativa $\mathbf{n}^{\circ}$ 77. Brasília, DF: MAPA. Diário Oficial da República Federativa do Brasil. Disponível em: https://www.gov.br/agricultura/pt-br/ . Acesso em 27 jun. 2018.

BRASIL. Ministério da Agricultura Pecuária e Abastecimento. (2018) Instrução Normativa no 76. Brasília, DF: MAPA. Diário Oficial da República Federativa do Brasil. Disponível em: https://www.gov.br/agricultura/pt-br/. Acesso em 27 jun. 2018.

BRASIL. Ministério da Agricultura Pecuária e Abastecimento. (2018) Manual de Métodos Oficiais para Análise de Alimentos de Origem Animal. Brasília, DF: MAPA. Diário Oficial da República Federativa do Brasil. Disponível em: https://www.gov.br/agricultura/pt-br/. Acesso em 27 jun. 2018.

BRASIL. Ministério da Agricultura Pecuária e Abastecimento. Instrução Normativa $\mathbf{n}^{\circ} 68$ de 12 de dezembro de 2006. Brasília, DF: MAPA, 2006. Disponível em: https://www.gov.br/agricultura/pt-br/. Acesso em: 25 mai. 2018.

BRASIL. Ministério da Agricultura, Pecuária e Abastecimento. Decreto no 9.013, de 29 de março de 2017. Disponível em: https://www.gov.br/agricultura/pt-br/. Acesso em 27 jun. 2018.

BRASIL. Ministério da Agricultura, Pecuária e Abastecimento. Instrução Normativa no 13, de 29 de maio de 2014. Diário Oficial da República Federativa do Brasil, Brasília, 13 mai. 2014. Seção 1, p. 55. Disponível em: https://www.gov.br/agricultura/pt-br/ . Acesso em 27 jun. 2018.

BRITO, M. A. V. P. Resíduos de antimicrobianos no leite. Juiz de Fora: Embrapa Gado de 
Leite, 2005. 28 p. Disponível em: https://www.embrapa.br/. Acesso em: Acesso em 27 jul. 2020 .

BRITO, M. A. V. P.; ARCURI, E. F.; BRITO, J. R. F. Testando a qualidade do leite. In: MINAS LEITE, 2, 2000, Juiz de Fora. Anais... Juiz de Fora: Embrapa Gado de Leite, 2000. p. 83-94. Disponível em: http://www.bdpa.cnptia.embrapa.br/. Acesso em: 27 jul. 2020.

Brito, M. A. V. P.; BRITO, J. R. F. Qualidade do leite. 2009. Disponível em: http://www.fernandomadalena.com/site_arquivos/903.pdf. Acesso em: 28 jul. 2020.

BUENO, V. F. F et al. Contagem celular somática: relação com a composição centesimal do leite e período do ano no Estado de Goiás. Ciência Rural, Santa Maria, v. 35, n. 4, p. 848$854,2005$.

CASSOLI, L.D.; Uma pergunta Simples: A qualidade do leite tem melhorado nos últimos anos? Milkpoint. 2012. Disponível em: https://www.milkpoint.com.br/noticias-e-mercado/gironoticias/uma-pergunta-simples-a-qualidade-do-leite-tem-melhorado-nos-ultimos-anos79994n.aspx?r=669428400\#. Acesso em: 25 jul 2020.

COENTRÃO, C.M. et al. Fatores de risco para mastite subclínica em vacas leiteiras. Arquivo Brasileiro de Medicina Veterinária e Zootecnia, [S.1.], v. 60, n. 2, p. 283-288, abr. 2008. http://dx.doi.org/10.1590/s0102-09352008000200001. Disponível em: https://www.scielo.br/. Acesso em: 20 jul. 2020.

COSTA, H. N. et al. Estimativa das perdas de produção leiteira em vacas mestiças Holandês x Zebu com mastite subclínica baseada em duas metodologias de análise. Arquivo Brasileiro de Medicina Veterinária e Zootecnia, [S.1.], v. 69, n. 3, p. 579-586, jun. 2017. http://dx.doi.org/10.1590/1678-4162-9019. Disponível em: www.scielo.br/. Acesso em: 20jul. 2020.

DÜRR, J. W. Programa nacional de melhoria da qualidade do leite: uma oportunidade única. In: Dürr J. W., Carvalho M. P., Santos M. V. (Eds.) O compromisso com a qualidade do leite no Brasil. Passo Fundo: Editora Universidade de Passo Fundo, p. 38-55, 2004. 
ECKSTEIN, I. I. et al. Contagem Bacteriana Total e Contagem de Células Somáticas do leite cru em diferentes tipos e tempos de resfriamento. In: CONGRESSO BRASILEIRO DE QUALIDADE DO LEITE. 4. 2010. Florianópolis. Anais... Florianópolis: CAV, 2010.

EIFERT, E. C. et. al. Consumo, produção e composição do leite de vacas alimentadas com óleo de soja e diferentes fontes de carboidratos na dieta. Revista Brasileira Zootecnia, v. 35, n. 1, p. 211-218, 2006.

FERRÃO, M. F. et al. LS-SVM: uma nova ferramenta quimiométrica para regressão multivariada. Comparação de modelos de regressão ls-svm e pls na quantificação de adulterantes em leite em pó empregando nir. Química Nova, [S.1.], v. 30, n. 4, p. 852-859, ago. 2007. http://dx.doi.org/10.1590/s0100-40422007000400018. Disponível em: www.scielo.br/. Acesso em: 25 jul. 2020.

FIRMINO, F. C. et al. DETECÇÃO DE FRAUDES EM LEITE CRU DOS TANQUES DE EXPANSÃO DA REGIÃO DE RIO POMBA, MINAS GERAIS. Revista do Instituto de Laticínios Cândido Tostes, [S.1.], v. 376, n. 65, p. 5-11, set. 2010. Disponível em: www.revistadoilct.com.br. Acesso em: 25 jul. 2020.

FORNASARI, M. T. C.; MONTANHINI, M. T. M. Avaliação da Eficiência da Prova Qualitativa de Cloretos para Investigação de Adulteração do Leite. Rebrapa: Brazilian Journal of Food Research. [S.1.], p. 75-79. 26 maio 2015. Disponível em: https://portalpubvet.com.br/. Acesso em: 25 jul. 2020.

FORNASARI, M. T. C.; MONTANHINI, M. T. M. Avaliação da Eficiência da Prova Qualitativa de Cloretos para Investigação de Adulteração do Leite. Rebrapa: Brazilian Journal of Food Research. [S.1.], p. 75-79.26 maio 2015. Disponível em: https://portalpubvet.com.br/. Acesso em: 25 jul. 2020.

GERMANO, P. M. L.; GERMANO, M. I. S. Higiene e vigilância sanitária de alimentos: qualidades das matérias-primas, doenças transmitidas por alimentos, treinamento de recursos humanos. Embrapa. São Paulo, 3 ed. p. 1-986, 2008. 
JUNIOR, R. B. R. Influência da mastite na ocorrência de resíduos de antimicrobianos no leite. 2001. 106 f. Dissertação (Mestrado) - Curso de Farmácia, Universidade de São Paulo, [S.1.], 2001. Disponível em: https://teses.usp.br/. Acesso em: 25 jul. 2020.

LIMA, M. C. G. et al. Contagem de células somáticas e análises físico-químicas e microbiológicas do leite cru tipo C produzido na região Agreste do estado de Pernambuco. Arquivo Instituto Biológico, São Paulo, v. 73, n. 1, p. 89-95, mar. 2006. Disponível em: www.biologico.agricultura.sp.gov.br. Acesso em: 25 jul. 2020.

MACEDO, L.; FREITAS, J. Ocorrência de resíduos de antimicrobianos em leite. Revista de Ciências Agrárias - Amazonian Journal of Agricultural and Environmental Sciences, América do Norte, 52, mar. 2009. Disponível em: http://www.ajaes.ufra.edu.br/. Acesso em: 20 Jul. 2020.

MARTIN, P. et al. Symposium review: novel strategies to genetically improve mastitis resistance in dairy cattle. Journal Of Dairy Science, [S.1.], v. 101, n. 3, p. 2724-2736, mar. 2018. http://dx.doi.org/10.3168/jds.2017-13554. Disponível em: https://pubmed.ncbi.nlm.nih.gov/29331471/. Acesso em: 20 jul. 2020.

MARTINS, J. D. et al. Subclinical mastitis in dairy cattle rural properties Goiás. Revista Brasileira de Higiene e Sanidade Animal, [S.1.], v. 9, n. 2, p. 206-214, 2015. http://dx.doi.org/10.5935/1981-2965.20150019. Disponível em: https://repositorio.bc.ufg.br/xmlui/handle/ri/12439. Acesso em: 25 jul. 2020.

NASCIMENTO, G. G. F.; MAESTRO, V.; CAMPOS, M. S. P. Ocorrência de resíduos de antibióticos no leite comercializado em Piracicaba, SP. Revista de Nutrição, [S.1.], v. 14, n. 2, p. 119-124, Ago. 2001. http://dx.doi.org/10.1590/s141552732001000200005. Disponível em: https://www.scielo.br/. Acesso em: 25 jul. 2020.

NERO, L. A. et al. Resíduos de antibióticos em leite cru de quatro regiões leiteiras no Brasil. Ciência e Tecnologia de Alimentos, [S.1.], v. 27, n. 2, p. 391-393, jun. 2007. http://dx.doi.org/10.1590/s0101-20612007000200031. Disponível em: https://www.scielo.br/. Acesso em: 25 jul. 2020. 
NETA, F. C. C. N. et al. AVALIAÇÃO DA QUALIDADE DE LEITE CRU ARMAZENADO EM TANQUES DE REFRIGERAÇÃO NO MUNICÍPIO DE ALEGRE, ESPÍRITO SANTO. Revista Brasileira de Agropecuária Sustentável, [S.1.], v. 6, n. 3, p. 21-27, 30 set. 2016. http://dx.doi.org/10.21206/rbas.v6i3.333. Disponível em: https://periodicos.ufv.br/. Acesso em: 25 jul. 2020.

OLIVEIRA, R. R. et al. Determinação do caseinomacropeptídeo em leite UAT por espectroscopia no infravermelho próximo e regressão por mínimos quadrados parciais. Arquivo Brasileiro de Medicina Veterinária e Zootecnia, [S.1.], v. 70, n. 3, p. 946- 956, jun. 2018. http://dx.doi.org/10.1590/1678-4162-9778. Disponível em:

https://www.scielo.br/. Acesso em: 20 jul. 2020.

ORGANIZAÇÃO DAS NAÇÕES UNIDAS PARA ALIMENTAÇÃO E AGRICULTURA. PADRÃO GERAL CODEX PARA A ROTULAGEM DE ALIMENTOS PRÉEMBALADOS: CODEX GENERAL STANDARD FOR THE

LABELLING OF PREPACKAGED FOODS. Roma: Fao, Viale Delle Terme di Caracalla, 1991. Disponível em: www.codexalimentarius.net. Acesso em: 20 jul. 2020.

PEREIRA, A. R. et al. Efeito do nível de células somáticas sobre os constituintes do leite Igordura e proteína. Brazilian Journal Of Veterinary Research And Animal Science, [S.1.], v. 36, n. 3, p. 121-124, jan. 1999. http://dx.doi.org/10.1590/s1413-95961999000300003.

Disponível em: https://www.scielo.br/. Acesso em: 20 jul. 2020.

PEREIRA, J. C. Vacas leiteiras: aspectos práticos da alimentação. Viçosa, MG: Aprenda Fácil, 2000. 198 p.PERES, 2001).

REIS, G. L. et al. Procedimentos de coleta de leite cru individual e sua relação com a composição físico-química e a contagem de células somáticas. Ciência Rural, Santa Maria, v. 37, n. 4, p. 1134-1138, 2007.

RIBEIRO, M. G. et al. Microrganismos patogênicos, celularidade e resíduos de antimicrobianos no leite bovino produzido no sistema orgânico. Pesquisa Veterinária Brasileira, [S.1.], v. 29, 
n. 1, p. 52-58, jan. 2009. Http://dx.doi.org/10.1590/s0100- 736x2009000100008. Disponível em: https://www.scielo.br/. Acesso em: 25 jul. 2020.

ROBIM, M. S. et al. Research fraud in UHT whole milk marketed in the state of Rio de Janeiro and comparison between the methods of physicochemical officers and the method of ultrasound. Revista do Instituto de Laticínios Cândido Tostes, [S.1.], v. 67, n. 389, p. 43-50, 2012. http://dx.doi.org/10.5935/2238-6416.20120077. Disponível em: https://www.revistadoilct.com.br. Acesso em: 20 jul. 2020.

ROSA, L. S. et al. Avaliação da qualidade do leite cru e resfriado mediante a aplicação de princípios do APPCC. Ciência e Tecnologia de Alimentos, [S.1.], v. 27, n. 2, p. 422-430, jun. 2007. http://dx.doi.org/10.1590/s0101-20612007000200036. Disponível em: https://www.scielo.br/. Acesso em: 25 jul. 2020.

SAEKI, Erika K.; MATSUMOTO, Leopoldo S. CONTAGEM DE MESÓFILOS E PSICROTRÓFICOS EM AMOSTRAS DE LEITE PASTEURIZADO E UHT. Revista do Instituto de Laticínios Cândido Tostes, [S.1.], v. 65, n. 377, p. 29-35, nov. 2010. Disponível em: https://www.revistadoilct.com.br/. Acesso em: 25 jul. 2020.

SANTOS, M. V.; LARANJA-DA-FONSECA, L. F. Estratégias para controle de mastite e melhoria da qualidade do leite. [S.1.]: Manole, 2007. 314 p.

SILVA, F.R. et al. Resíduos de Antibióticos em Leite Cru Refrigerado. In: I Congresso de Pesquisa e Pós-Graduação do Campus Rio Verde do IFGoiano. 06 e 07 de novembro de 2012 .

SILVA, L. C. C. et al. Heat stability of casein and ethanol stability at 68, 72, 75 e 78\%, in bovine milk. Revista do Instituto de Laticínios Cândido Tostes, [S.1.], v. 67, n. 384, p. 5560, 2012. http://dx.doi.org/10.5935/2238-6416.20120008. Disponível em: https://www.revistadoilct.com.br/. Acesso em: 20 jul. 2020.

SILVA, R. C. S. N. et al. Number of judges necessary for descriptive sensory tests. Food Quality And Preference, [S.1.], v. 31, p. 22-27, jan. 2014. 
Http://dx.doi.org/10.1016/j.foodqual.2013.07.010. Disponível em: https://www.sciencedirect.com/. Acesso em: 20 jul. 2020.

TEIXEIRA, N. M.; FREITAS, A. F.; BARRA, R. B. Influência de fatores de meio ambiente na variação mensal da composição e contagem de células somáticas do leite em rebanhos no Estado de Minas Gerais. Revista Arquivo Brasileiro Medicina Veterinária Zootecnia, Belo Horizonte, v. 55, n. 4, p. 491-499, 2003.Campos et al., (2006).

TRONCO, V. M. Manual para Inspeção da Qualidade do Leite. 3. ed. Santa Maria: Editora UFSM, 2008; 206p.

UNITED STATES ENVIRONMENTAL PROTECTION AGENCY. Chlorine. [S.1.], 2000.

Disponível em: https://19january2017snapshot.epa.gov/sites/production/files/201609/documents/chlorine.pdf. Acesso em: 20 jul. 2020.

VALLIN, V. M. et al; Melhoria da qualidade do leite a partir da implantação de boas práticas de higiene na ordenha em 19 municípios da região central do Paraná. Semina: Ciências Agrárias, Londrina, v. 30, n. 1, p. 181-188, jan. 2009. Disponível em: https://www.bvsvet.org.br/. Acesso em: 25 jul. 2020.

VIRGINIA TECH. PUBLICATION 404-400: Cleaning and Sanitizing Milking Equipment. [S.1.]: Dairy Science, 2009. Disponível em: https://www.pubs.ext.vt.edu/404/404-400/404400.html. Acesso em: 20 jul. 2020.

ZANELA, M. B. Qualidade do leite em sistemas de produção na região Sul do Rio Grande do Sul. Revista Pesquisa Agropecuária Brasileira, Santa Maria, v. 41, n. 1, p. 153-159, 2006. 